\title{
Effects of acidity and inorganic ions on the photocatalytic degradation of different azo dyes
}

\author{
C. $\mathrm{Hu}^{\mathrm{a}}{ }^{\mathrm{b}}$, Jimmy C. Yu ${ }^{\mathrm{c}}$, Z. Hao ${ }^{\mathrm{b}}$, P.K. Wong ${ }^{\mathrm{a}, *}$ \\ a Department of Biology, The Chinese University of Hong Kong, Shatin, NT, Hong Kong SAR, China \\ ${ }^{\mathrm{b}}$ Research Center for Eco-Environmental Sciences, Chinese Academy of Sciences, Beijing 100085, China \\ ${ }^{\mathrm{c}}$ Department of Chemistry, The Chinese University of Hong Kong, Shatin, NT, Hong Kong SAR, China
}

Received 13 February 2003; received in revised form 27 March 2003; accepted 4 April 2003

\begin{abstract}
Effects of acidity and inorganic ions that are common in industrial effluent on the photocatalytic degradation of azo dyes, Procion Red MX-5B (MX-5B) and Cationic Blue X-GRL (CBX), have been investigated in UV illuminated $\mathrm{TiO}_{2}$ dispersions. There are significant differences between adsorption and photodegradation of MX-5B and those of CBX to the change of solution $\mathrm{pH}$. The results indicated that $\mathrm{CBX}$ photodegradation was favored at the surface of $\mathrm{TiO}_{2}$, while that of $\mathrm{MX}-5 \mathrm{~B}$ occurred in the aqueous phase. At $\mathrm{pH} 2.4, \mathrm{SO}_{4}{ }^{2-}, \mathrm{H}_{2} \mathrm{PO}_{4}{ }^{-}, \mathrm{ClO}_{4}{ }^{-}$and $\mathrm{F}^{-}$in general increased the decolorization rates of MX-5B and CBX by enhancing the adsorption of the selected dyes on the surface of $\mathrm{TiO}_{2}$. At pH 10.8, most of the selected anions inhibited the photocatalytic oxidation (PCO) to decolorize and degrade $\mathrm{CBX}$ and $\mathrm{MX}-5 \mathrm{~B}$. These results demonstrated that inorganic anions affect the photodegradation of dyes by their adsorption onto the surface of $\mathrm{TiO}_{2}$ and trapping positive hole $\left(\mathrm{h}^{+}\right)$and ${ }^{\bullet} \mathrm{OH}$. Inorganic cationic ions, such as $\mathrm{Cu}^{2+}$ and $\mathrm{Ni}^{2+}$ had strong inhibition on the PCO decolorization of MX-5B at $\mathrm{pH}$ 10.8. On the contrary, no significant effect was observed at the same concentration of metal cations at $\mathrm{pH} 2.4$.
\end{abstract}

() 2003 Elsevier Science B.V. All rights reserved.

Keywords: Adsorption; Azo dyes; Deactivation; Photodegradation; Inorganic ions

\section{Introduction}

Heterogeneous photocatalytic oxidation (PCO) for wastewater treatment has received much attention by various research groups. Numerous types of catalysts and contaminants have been investigated on laboratory scale $[1,2]$. However, very few commercial applications of this technology are available at present. One of the major reasons is the deactivation of the photocatalyst when photocatalysis is utilized

\footnotetext{
* Corresponding author. Tel.: +852-2609-6383; fax: $+852-2603-6767$.

E-mail address: pkwong@cuhk.edu.hk (P.K. Wong).
}

to treat real wastewater [3]. Therefore, information on the long-term activity of photocatalysts is needed for the application of photocatalysis. Heterogeneous photocatalysis is a process in which the illumination of an oxide semi-conductor, usually $\mathrm{TiO}_{2}$ in the form of anatase or rutile, produces photo-excited electrons $\left(\mathrm{e}^{-}\right)$and positive charged holes $\left(\mathrm{h}^{+}\right)$. The photo-excitation of the semi-conductor particles by UV light changes the energy state of the electrons from the valence band of the solid to the conduction band. The formation of active species was previously discussed in detail [4]. The effects of salty water on the PCO products of liquid 3-octanol and 3-octanone were studied [5]. A number of studies have examined 
the effect of various inorganic ions on $\mathrm{TiO}_{2}$ slurry photocatalysts $[6,7]$ and on fixed-bed photocatalysts where the $\mathrm{TiO}_{2}$ was attached to a support, e.g. the inside wall of a borosilicate glass spiral [5,8], and the surface of porous silica gel or fiberglass mesh [9]. There seems to be a general consensus that the effect of organic ions on photocatalysis depends on geometric configuration of the reactor and the structures of the organic compounds to be degraded.

Organic dyes are one of the major groups of pollutants in wastewaters produced from textile and other industrial processes [10]. These wastewaters are highly colored. The more complex environmental problem associated with the textile industry is that organic dyes are resistant to microbial degradation and they can be converted to toxic or carcinogenic compounds [11]. Heterogeneous photocatalysis has been considered as a cost-effective alternative as pre- or post-treatment of the biological treatment process for the purification of dye-containing wastewater $[11,12]$. The occurrence of dissolved inorganic ions is rather common in dye-containing industrial wastewaters. They can significantly influence the photocatalytic reactions for the treatment of dyes. A study on the effects of inorganic ions on PCO degradation of dye will therefore be very useful for understanding the mechanism of the photocatalytic decolorization of dyes in $\mathrm{TiO}_{2}$ dispersions under UV irradiation.

In this paper, we examined the effects of several types of inorganic ions $\left(\mathrm{SO}_{4}{ }^{2-}, \mathrm{H}_{2} \mathrm{PO}_{4}{ }^{-}, \mathrm{ClO}_{4}{ }^{-}\right.$, $\mathrm{F}^{-}, \mathrm{Cu}^{2+}$ and $\mathrm{Ni}^{2+}$ ) that are common in synthetic dye-containing effluent on the photodegradation of two selected azo dyes in $\mathrm{TiO}_{2}$ aqueous dispersions under UV irradiation. These two azo dyes have different adsorption modes on the surface of $\mathrm{TiO}_{2}$.
The photodegradation rates showed different patterns with the changes of $\mathrm{pH}$. In addition, the effects of different inorganic ions on and the mechanisms of photodegradation of these two azo dyes were discussed.

\section{Experimental}

\subsection{Chemicals}

$\mathrm{TiO}_{2}$ (P-25, ca. $80 \%$ anatase, $20 \%$ rutile; BET area, ca. $50 \mathrm{~m}^{2} \mathrm{~g}^{-1}$ ) was obtained from Degussa Co., Germany. The azo dye, Procion Red MX-5B (MX-5B), shown in Fig. 1A was manufactured by Imperial Chemicals Industries. Another azo dye, Cationic Blue X-GRL (CBX) shown in Fig. 1B, was provided by Shanghai Chemical Company, China. They were used without further purification. All other reagents were analytical grade. The $\mathrm{pH}$ of the solution was adjusted with $\mathrm{HCl}$ or $\mathrm{NaOH}$.

\subsection{Adsorption experiments}

All equilibrium adsorption studies were performed in a $50 \mathrm{ml}$ suspension with $25 \mathrm{mg}$ of $\mathrm{TiO}_{2}$. The suspension was equilibrated overnight in a temperature-controlled incubation shaker at $23 \pm 2{ }^{\circ} \mathrm{C}$. The appropriate addition of acid $(2 \mathrm{~N}, \mathrm{HCl})$ or base $(3 \mathrm{~N}, \mathrm{NaOH})$ was made to adjust required $\mathrm{pH}$, respectively. The samples were kept in the dark for the entire period of the experiments in order to avoid photo-excitation of the $\mathrm{TiO}_{2}$. The rate of dye decolorization was monitored by a Milton Roy Spectronic 3000 Array spectrophotometer.

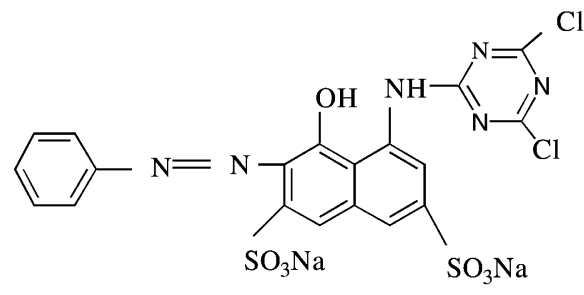

(A)

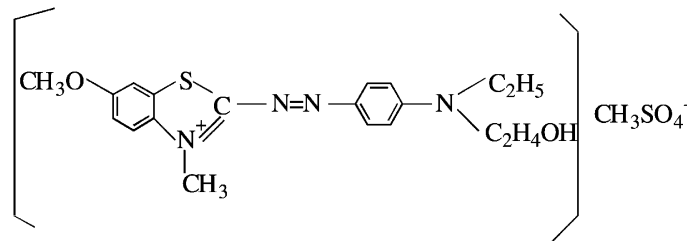

(B)

Fig. 1. Structures of azo dyes: (A) MX-5B and (B) CBX. 


\subsection{Photocatalytic degradation experiments}

A laboratory-scale photoreactor consisted of a open Pyrex glass column $(430 \mathrm{~mm}$ height, $25 \mathrm{~mm}$ external diameter, and with a wall $1.5 \mathrm{~mm}$ thick) surrounded by eight $365 \mathrm{~nm}$ UV fluorescent tubes (Viber-lourmat, Model T-15 L/8D) with a power consumption rate of $15 \mathrm{~W}$ and an average UV output intensity of $2.13 \mathrm{~mW} \mathrm{~cm}^{-2}$ as determined at the center of the photoreactor [13]. The total UV intensity was controlled by turning on different number of UV lamps. During PCO reaction, the solution with $\mathrm{TiO}_{2}$ and dye solution was continuously aerated by a pump in order to provide $\mathrm{O}_{2}$ and complete mixing to reaction solution.
In dye degradation by PCO experiments, the $\mathrm{TiO}_{2}$ aqueous dispersions were prepared by addition of $75 \mathrm{mg}$ of $\mathrm{TiO}_{2}$ to $150 \mathrm{ml}$ aqueous solution containing the dyes and inorganic ions at different pHs. Prior to irradiation, the suspensions were mixed in dark for $30 \mathrm{~min}$ to ensure adsorption/desorption equilibrium. At given time intervals, $5 \mathrm{ml}$ aliquots were sampled, centrifuged, and then filtered through a Millipore filter (pore size $0.22 \mu \mathrm{m}$ ) in order to remove the $\mathrm{TiO}_{2}$ particles. The filtrates were analyzed by recording variations of the adsorption band maximum $(540 \mathrm{~nm}$ for MX-5B, $610 \mathrm{~nm}$ for CBX) in the UV-Vis spectra of the dyes using a Milton Roy Spectronic 3000 Array spectrophotometer.

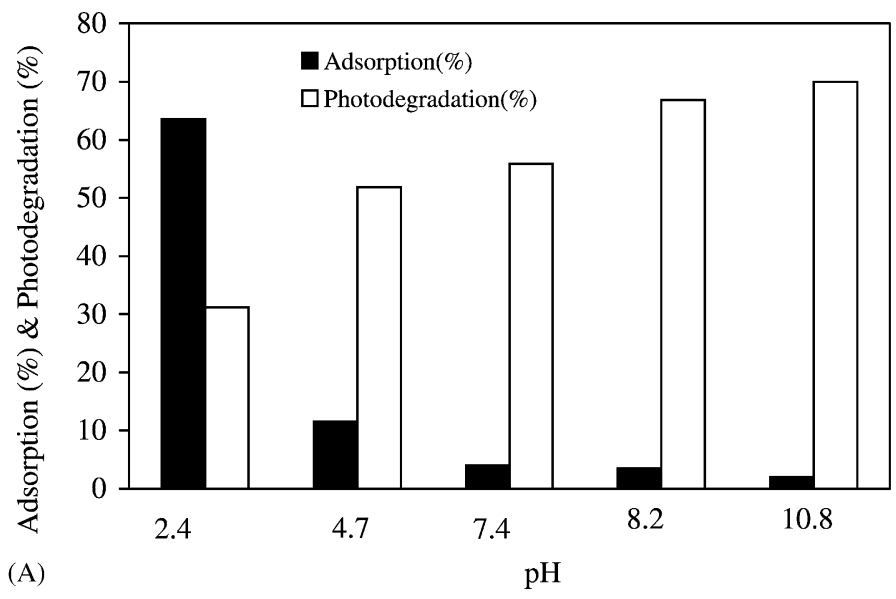

(A)

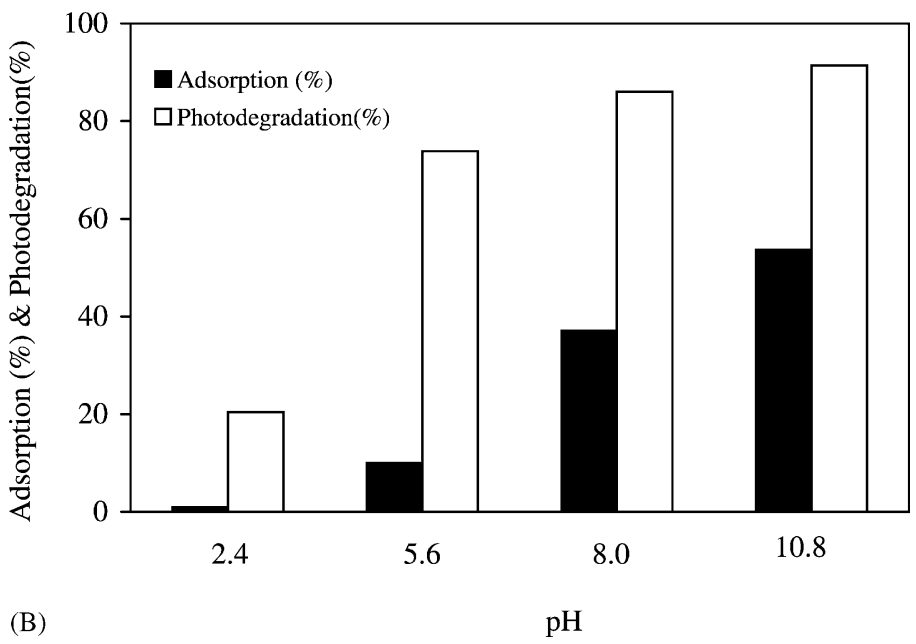

Fig. 2. The adsorption and photocatalytic decolorization of (A) MX-5B (irradiation time: 20 min) and (B) CBX (irradiation time: 10 min) at different $\mathrm{pHs}\left(\left[\mathrm{TiO}_{2}\right]=500 \mathrm{mgl}^{-1}, C_{0}=40 \mathrm{mgl}^{-1}, \mathrm{UV}=4.2 \mathrm{~mW} \mathrm{~cm}^{-2}\right)$. 


\section{Results and discussion}

\subsection{Effects of $p H$}

Fig. 2A and B shows the changes of adsorption and decolorization of MX-5B and CBX with $\mathrm{pH}$. Clearly, the adsorption of MX-5B decreased with $\mathrm{pH}$ increasing. However, the photodegradation rate of MX-5B increased under UV irradiation with the decrease of adsorption of MX-5B. We have confirmed in a pre- vious study that, in the decolorization of MX-5B, the more active bonds including the $\mathrm{C}-\mathrm{N}$ bonds linked to the benzene ring or the naphthalene ring were hydroxylated first [14]. The photodegradation of MX-5B therefore occurred in the bulk aqueous phase. On the contrary, the adsorption of CBX increased with $\mathrm{pH}$, and the decolorization of $\mathrm{CBX}$ was also accelerated with the adsorption of CBX. Because of the high dependency on adsorption, the decolorization of CBX occurred mainly on the surface of $\mathrm{TiO}_{2}$ [15].

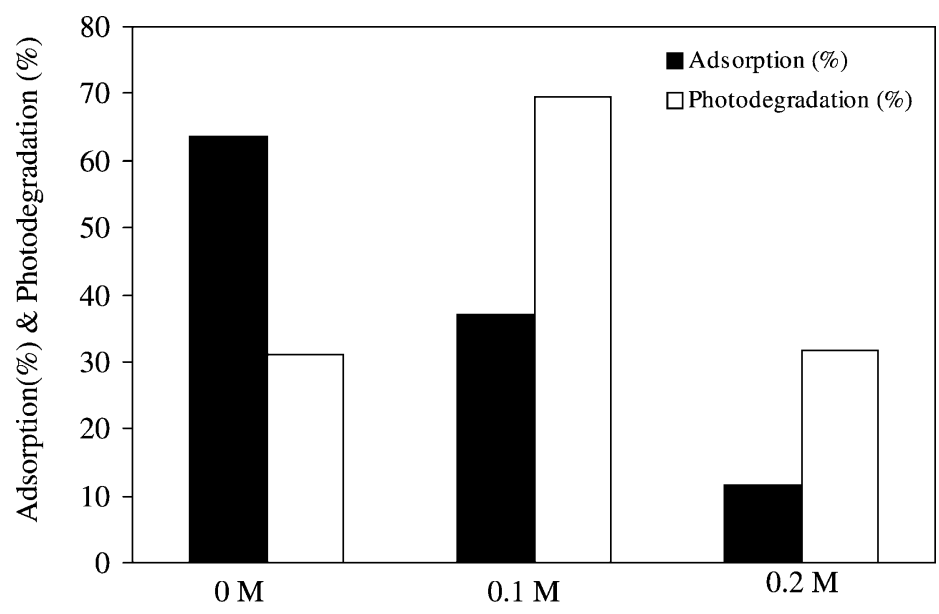

(A) $\quad \mathrm{Na}_{2} \mathrm{SO}_{4}$ concentration

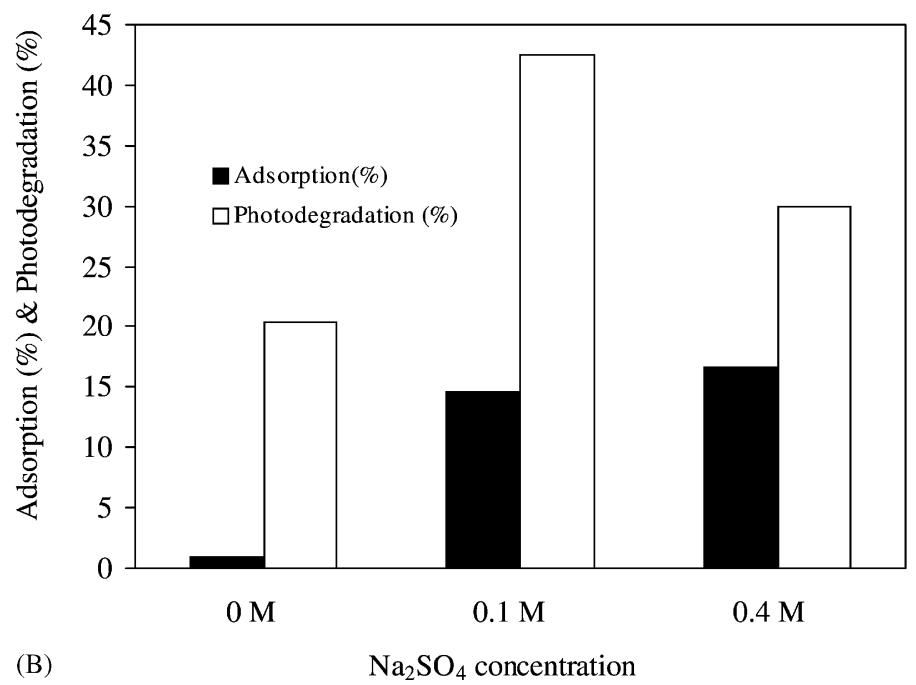

Fig. 3. The effects of different concentrations of $\mathrm{Na}_{2} \mathrm{SO}_{4}$ on the adsorption and photocatalytic degradation of (A) MX-5B (irradiation time: $20 \mathrm{~min}$ ) and (B) $\mathrm{CBX}$ (irradiation time: $10 \mathrm{~min}$ ) at $\mathrm{pH} 2.4\left(\left[\mathrm{TiO}_{2}\right]=500 \mathrm{mgl}^{-1}, C_{0}=40 \mathrm{mgl}^{-1}, \mathrm{UV}=4.2 \mathrm{~mW} \mathrm{~cm}^{-2}\right)$. 
The efficiencies of photocatalytic processes strongly depend upon the $\mathrm{pH}$ of the reaction solution. It was due to the amphoteric behavior of semi-conductor$\mathrm{TiO}_{2}$. The surface charge-property of $\mathrm{TiO}_{2}$ changes with the change of solution $\mathrm{pH}$. The point of zero charge (pzc) for $\mathrm{TiO}_{2}$ is 6.5. The $\mathrm{TiO}_{2}$ surface is positively charged in acidic solutions and negatively charged in basic solutions. The selected azo dyes had different adsorption behavior to the surface of $\mathrm{TiO}_{2}$. MX-5B was adsorbed on the surface of $\mathrm{TiO}_{2}$ by the sulfuric group [14], which was negatively charged, and the acidic solution favored adsorption of the dye onto photocatalyst surface. CBX was strongly adsorbed to the $\mathrm{TiO}^{-}$site of the photocatalyst by a penta-heterocyclic-N group, which was positively charged, and the basic solution favored adsorption of the dye onto photocatalyst surface [15].

\subsection{Effect of inorganic ions}

Anions, such as $\mathrm{SO}_{4}{ }^{2-}, \mathrm{ClO}_{4}{ }^{-}, \mathrm{H}_{2} \mathrm{PO}_{4}{ }^{-}$could be adsorbed on the surface of $\mathrm{TiO}_{2}$ in acidic conditions by
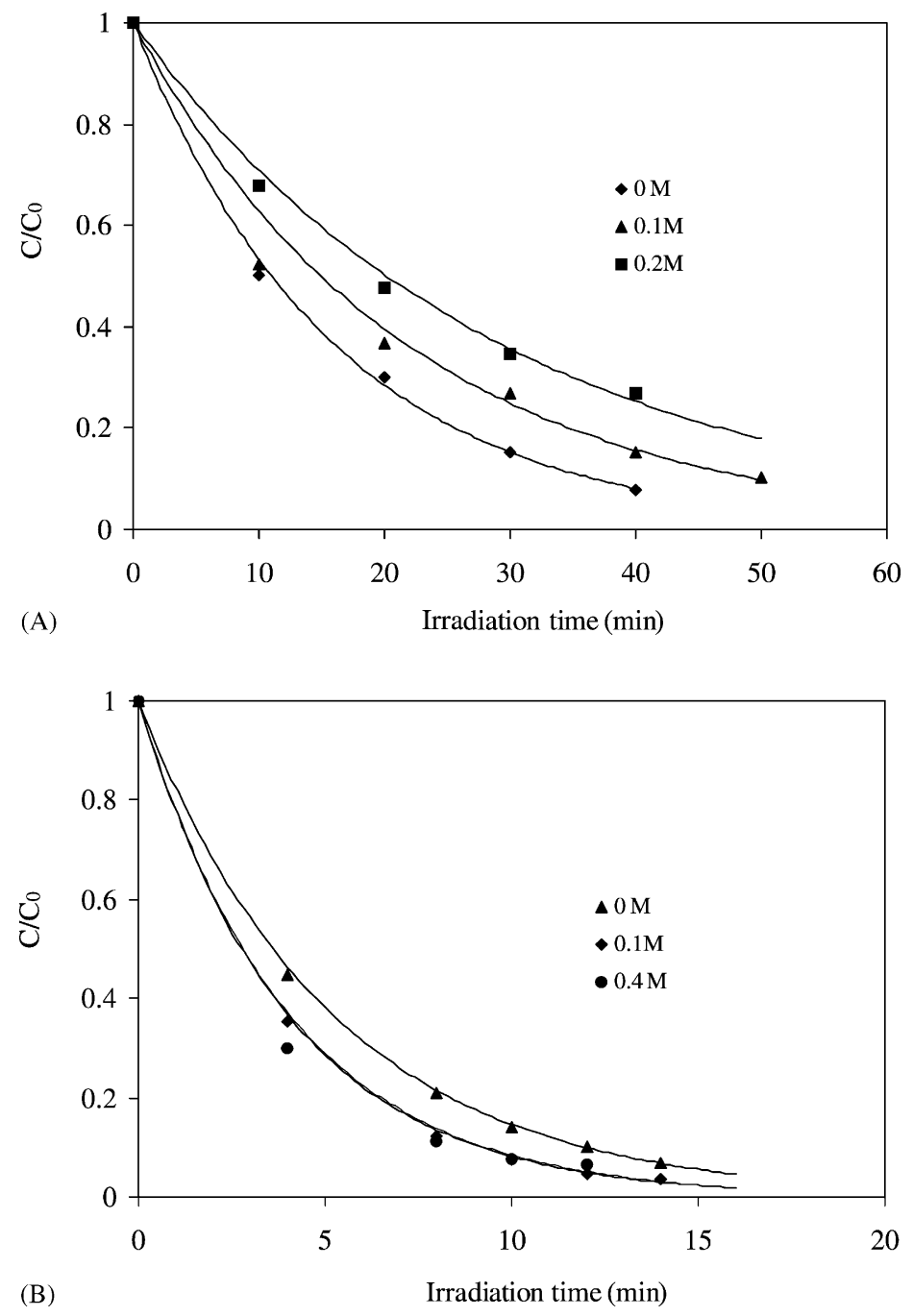

Fig. 4. The effect of $\mathrm{Na}_{2} \mathrm{SO}_{4}$ on the photodegradation of (A) $\mathrm{MX}-5 \mathrm{~B}$ at $\mathrm{pH} 10.8$ and (B) $\mathrm{CBX}$ at $\mathrm{pH} 8.0\left(\left[\mathrm{TiO}_{2}\right]=500 \mathrm{mgl}^{-1}\right.$, $C_{0}=40 \mathrm{mg} \mathrm{l}^{-1}, \mathrm{UV}=4.2 \mathrm{~mW} \mathrm{~cm}^{-2}$ ). 
electrostatic attraction. In alkaline solutions, such adsorption would be unlikely because of repulsive electrostatic force. In order to investigate the effect of these inorganic ions on the decolorization of dyes, a series of experiments were carried out in the presence of $\mathrm{TiO}_{2}$ with UV irradiation at different $\mathrm{pH}$ conditions.

\subsubsection{Effect of $\mathrm{SO}_{4}{ }^{2-}$ on the photodegradation of $M X-5 B$ and $C B X$}

Fig. 3A and $\mathrm{B}$ shows the changes of the adsorption and photocatalytic degradation of MX-5B and
CBX with increasing $\mathrm{Na}_{2} \mathrm{SO}_{4}$ concentration at $\mathrm{pH}$ 2.4. Obviously, with the increase of the $\mathrm{SO}_{4}{ }^{2-}$ concentration, the adsorption of MX-5B onto $\mathrm{TiO}_{2}$ decreased, whereas the adsorption of $\mathrm{CBX}$ onto $\mathrm{TiO}_{2}$ increased. The $\mathrm{TiO}_{2}$ surface is positively charged at $\mathrm{pH} 2.4, \mathrm{SO}_{4}{ }^{2-}$ was adsorbed onto negatively charged $\mathrm{TiO}_{2}$ surface by electrostatic attraction. Meanwhile, the $\mathrm{TiO}_{2}$ surface charge becomes less positive due to the adsorption of $\mathrm{SO}_{4}{ }^{2-}\left(\mathrm{SO}_{4}{ }^{2-}\right.$ holds the positive site on the surface of $\mathrm{TiO}_{2}$ ), leading to the increased adsorption of CBX onto $\mathrm{TiO}_{2}$. In the presence of

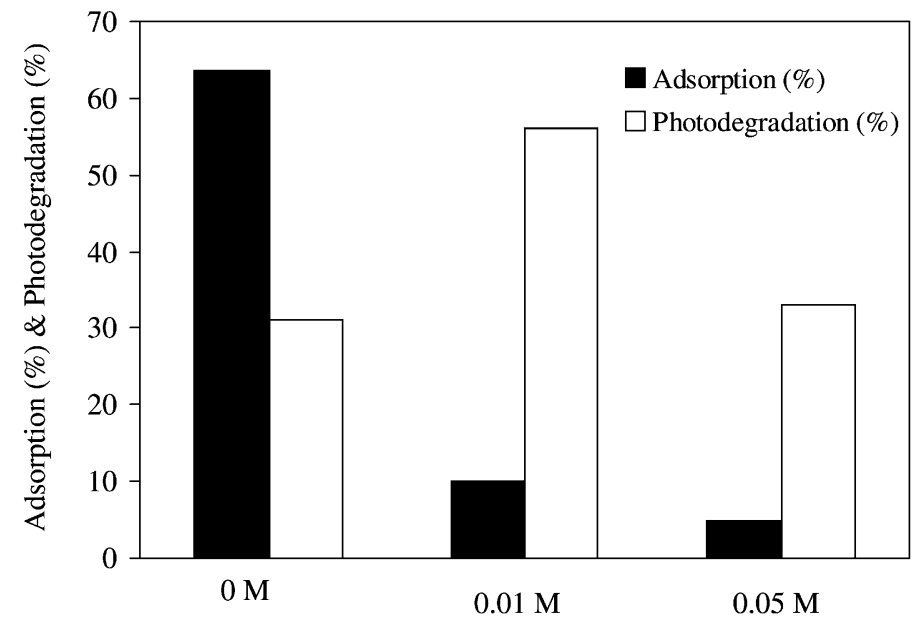

(A)

$\mathrm{NaH}_{2} \mathrm{PO}_{4}$ concentration

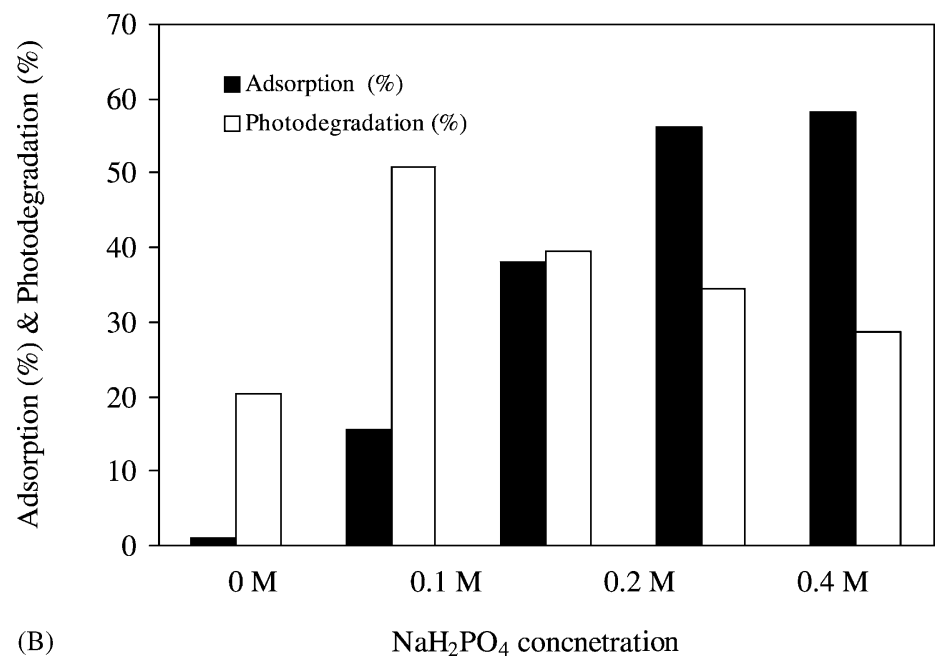

Fig. 5. The effects of different concentrations of $\mathrm{NaH}_{2} \mathrm{PO}_{4}$ on the adsorption and photodegradation of (A) MX-5B (irradiation time: 20 min) and (B) CBX (irradiation time: $10 \mathrm{~min}$ ) at $\mathrm{pH} 2.4\left(\left[\mathrm{TiO}_{2}\right]=500 \mathrm{mgl}^{-1}, C_{0}=40 \mathrm{mgl}^{-1}, \mathrm{UV}=4.2 \mathrm{~mW} \mathrm{~cm}^{-2}\right)$. 
$0.1 \mathrm{M} \mathrm{Na}_{2} \mathrm{SO}_{4}$, maximum photocatalytic decolorization was obtained for both MX-5B and CBX. When the $\mathrm{Na}_{2} \mathrm{SO}_{4}$ concentration was more than $0.1 \mathrm{M}$, the decolorization rates of $\mathrm{MX}-5 \mathrm{~B}$ and $\mathrm{CBX}$ decreased. The addition of $\mathrm{Na}_{2} \mathrm{SO}_{4}$ played two roles in the photodegradation of the selected dyes. The first one was that $\mathrm{SO}_{4}{ }^{2-}$ affected the PCO of the selected dyes by changing the surface charge of $\mathrm{TiO}_{2}$, resulting in a change of distribution of dye molecules between solution and $\mathrm{TiO}_{2}$ surface. Another was that the adsorbed $\mathrm{SO}_{4}{ }^{2-}$ reacted with the positive holes $\left(\mathrm{h}^{+}\right)$and hydroxyl radical $\left(\bullet^{\bullet} \mathrm{OH}\right)$, as shown in Eqs. (1) and (2):
$\mathrm{SO}_{4}{ }^{2-}+\mathrm{h}^{+} \rightarrow \mathrm{SO}_{4}^{\bullet-}$

$\mathrm{SO}_{4}{ }^{2-}+{ }^{\bullet} \mathrm{OH} \rightarrow \mathrm{SO}_{4}{ }^{\bullet-}+\mathrm{OH}^{-}$

$\mathrm{SO}_{4}{ }^{\bullet-}$ is less reactive than ${ }^{\bullet} \mathrm{OH}$ and $\mathrm{h}^{+}$, therefore, the excess $\mathrm{SO}_{4}{ }^{2-}$ hindered the photocatalytic decolorization of the selected dyes. Fig. 4A shows that the effect of different $\mathrm{SO}_{4}{ }^{2-}$ concentrations on the photodecolorization of MX-5B at strongly basic conditions. Obviously, the photodecolorization of MX-5B was significantly inhibited at all $\mathrm{SO}_{4}{ }^{2-}$ concentrations. For $\mathrm{SO}_{4}{ }^{2-}$ does not adsorbed on the negatively
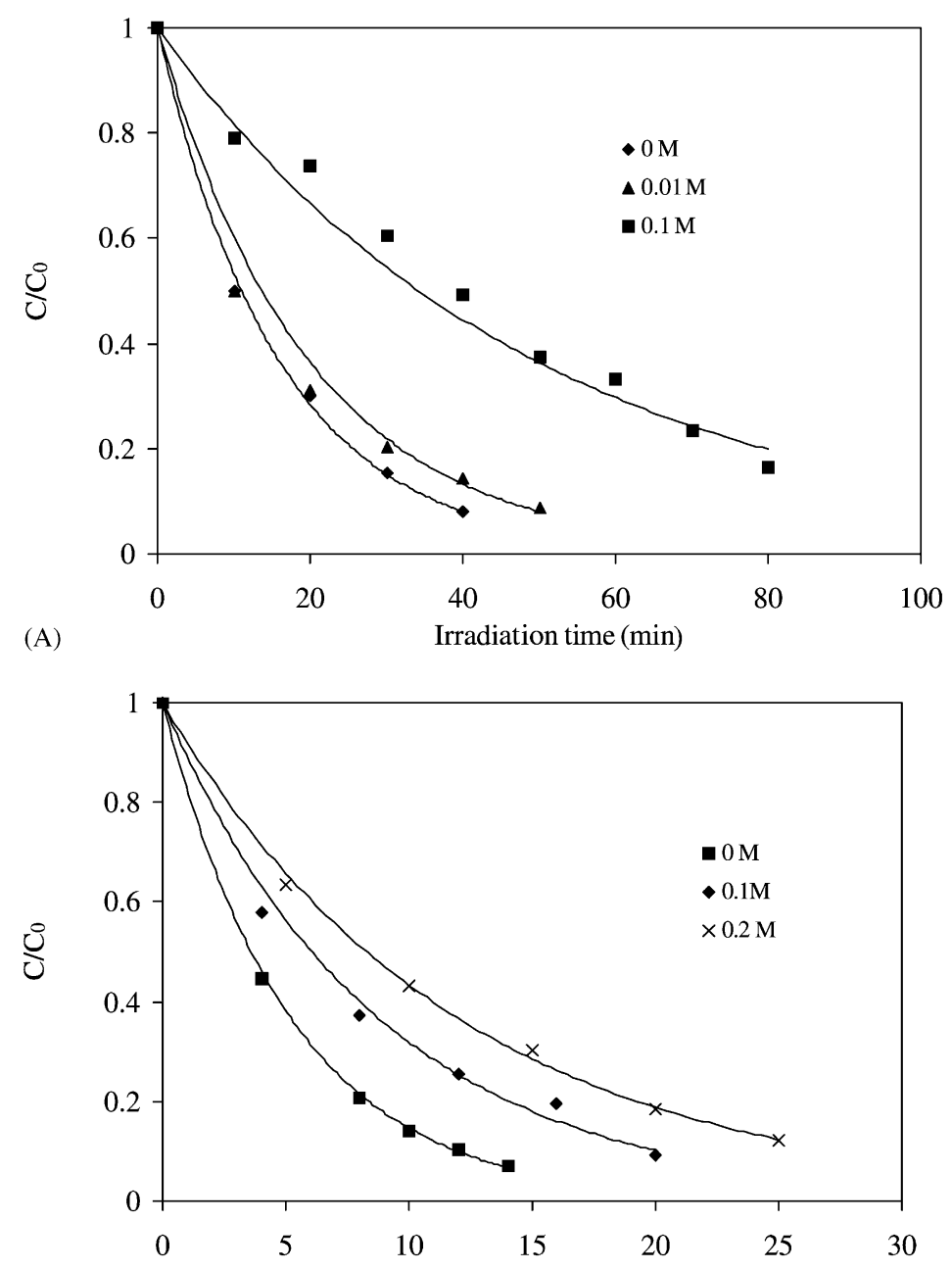

(B)

Irradiation time (min)

Fig. 6. The effect of $\mathrm{NaH}_{2} \mathrm{PO}_{4}$ on the photodegradation of $\mathrm{MX}-5 \mathrm{~B}$ (A) at $\mathrm{pH} 10.8$ and $\mathrm{CBX}(\mathrm{B})$ at $\mathrm{pH} 8.0\left(\left[\mathrm{TiO}_{2}\right]=500 \mathrm{mgl} \mathrm{l}^{-1}\right.$, $C_{0}=40 \mathrm{mgl}^{-1}, \mathrm{UV}=4.2 \mathrm{~mW} \mathrm{~cm}^{-2}$ ). 
charged surface of $\mathrm{TiO}_{2}$ at strong basic condition, the addition of $\mathrm{SO}_{4}{ }^{2-}$ had no influence on the adsorption of the selected dyes to $\mathrm{TiO}_{2}$. Most of the $\mathrm{SO}_{4}{ }^{2-}$ is available in the solution to trap ${ }^{\circ} \mathrm{OH}$, and the decolorization rate of dyes decreases. Fig. 4B shows an increase of the photocatalytic decolorization rate of $\mathrm{CBX}$ in the presence of $\mathrm{SO}_{4}{ }^{2-}$. At $\mathrm{pH} 8.0, \mathrm{SO}_{4}{ }^{2-}$ had no negative effect on the photodecolorization of CBX.

\subsubsection{Effect of phosphates}

The effects of $\mathrm{H}_{2} \mathrm{PO}_{4}{ }^{-}$on $\mathrm{PCO}$ rates were studied by adding $\mathrm{Na}_{2} \mathrm{H}_{2} \mathrm{PO}_{4}$ to solutions of MX-5B and
CBX. At pH 2.4, predominately $\mathrm{H}_{2} \mathrm{PO}_{4}{ }^{-}$is present. The effects observed were due to the adsorption of $\mathrm{H}_{2} \mathrm{PO}_{4}{ }^{-}$on the surface of the catalyst (Fig. 5A and B). As expected, with increasing $\mathrm{H}_{2} \mathrm{PO}_{4}{ }^{-}$concentrations, the adsorption of $\mathrm{MX}-5 \mathrm{~B}$ on $\mathrm{TiO}_{2}$ decreased, while the adsorption of $\mathrm{CBX}$ increased. Abdullah et al. [5] have proposed an adsorption mechanism based on an exchange reaction between the surface hydroxyl groups of $\mathrm{TiO}_{2}$ and $\mathrm{H}_{2} \mathrm{PO}_{4}{ }^{-}$. As shown in Fig. 5A and $\mathrm{B}$, the maximum photocatalytic decomposition rates of $\mathrm{MX}-5 \mathrm{~B}$ and $\mathrm{CBX}$ were recorded at a $\mathrm{NaH}_{2} \mathrm{PO}_{4}$ concentration of $0.01 \mathrm{M}$. When $\mathrm{NaH}_{2} \mathrm{PO}_{4}$

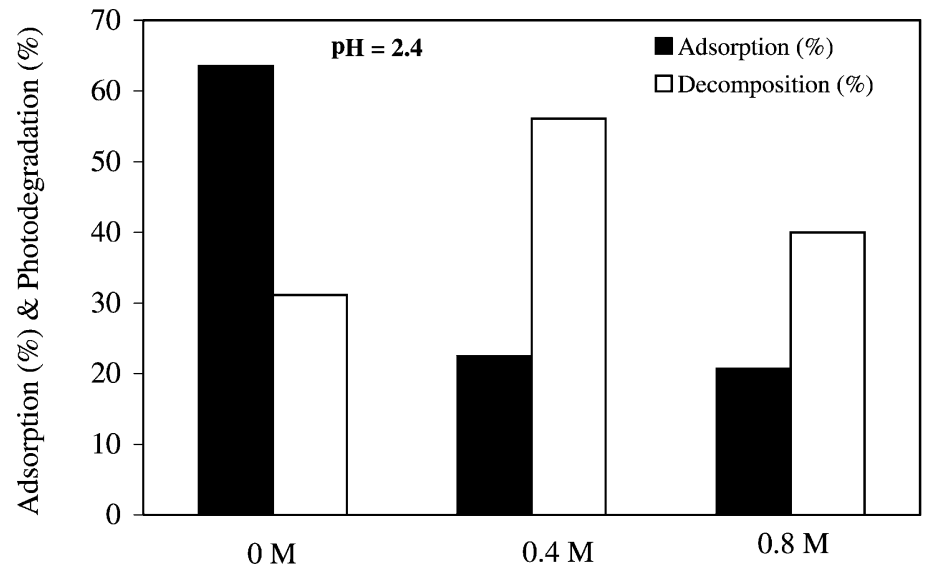

(A)

$\mathrm{NaClO}_{4}$ concenntration

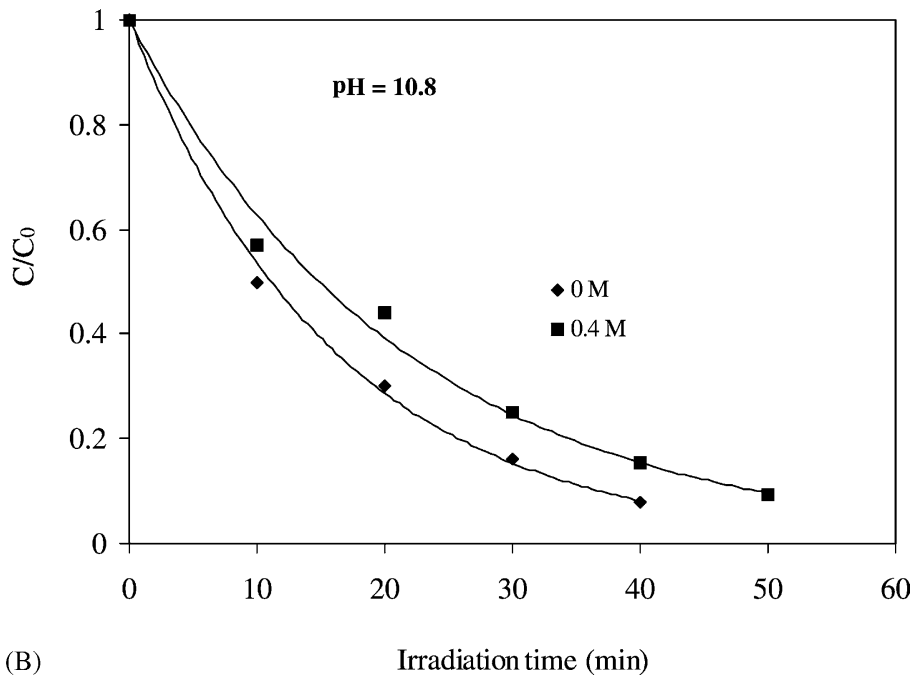

Fig. 7. The effects of different concentrations of $\mathrm{NaClO}_{4}$ on the adsorption and photodegradation of (A) MX-5B (irradiation time: 20 min) at $\mathrm{pH} 2.4$ and (B) MX-5B under $\mathrm{pH} 10.8\left(\left[\mathrm{TiO}_{2}\right]=500 \mathrm{mgl}^{-1}, C_{0}=40 \mathrm{mgl}^{-1}, \mathrm{UV}=4.2 \mathrm{~mW} \mathrm{~cm}^{-2}\right)$. 
concentration was more than $0.01 \mathrm{M}$, the photodegradation of MX-5B and $\mathrm{CBX}$ decreased with increasing $\mathrm{NaH}_{2} \mathrm{PO}_{4}$ concentrations. The behavior of $\mathrm{H}_{2} \mathrm{PO}_{4}{ }^{-}$ was similar to $\mathrm{SO}_{4}{ }^{2-}$ in that photocatalytic activity first increased then decreases with $\mathrm{H}_{2} \mathrm{PO}_{4}{ }^{-}$concentration. The $\mathrm{H}_{2} \mathrm{PO}_{4}{ }^{-}$reacted with $\mathrm{h}^{+}$and ${ }^{\bullet} \mathrm{OH}$ to form $\mathrm{H}_{2} \mathrm{PO}_{4}{ }^{\bullet}$, which is similar to $\mathrm{SO}_{4}{ }^{\bullet-}$. However, both $\mathrm{H}_{2} \mathrm{PO}_{4}{ }^{\bullet}$ and $\mathrm{SO}_{4}{ }^{\bullet-}$ are not as reactive as $\mathrm{h}^{+}$ and ${ }^{\bullet} \mathrm{OH}$. At strong basic conditions, the rates of photocatalytic decomposition of MX-5B and CBX were slowed down in the presence of $\mathrm{NaH}_{2} \mathrm{PO}_{4}$ (Fig. 6A and $\mathrm{B})$. No significant adsorption influence was ob- served at the selected $\mathrm{NaH}_{2} \mathrm{PO}_{4}$ concentration. In strong basic condition ( $\mathrm{pH} 10.8$ or 8.0 ), the main anions in solution were $\mathrm{HPO}_{4}{ }^{2-}$ and $\mathrm{PO}_{4}{ }^{3-}$. They reacted with ${ }^{\bullet} \mathrm{OH}$ to form $\mathrm{HPO}_{4}{ }^{\bullet-}$ and $\mathrm{PO}_{4}{ }^{\bullet-}$, which are somewhat less reactive [16]. The phosphate has a stronger inhibition effect for the photodegradation of dyes at high $\mathrm{pH}$ conditions.

\subsubsection{Effect of $\mathrm{ClO}_{4}{ }^{-}$}

Fig. 7A and $\mathrm{B}$ shows the effect of $\mathrm{NaClO}_{4}$ on the photodegradation of MX-5B at $\mathrm{pH} 2.4$ and 10.8. At $\mathrm{pH}$ 2.4, the addition of $\mathrm{NaClO}_{4}$ to solution decreased the
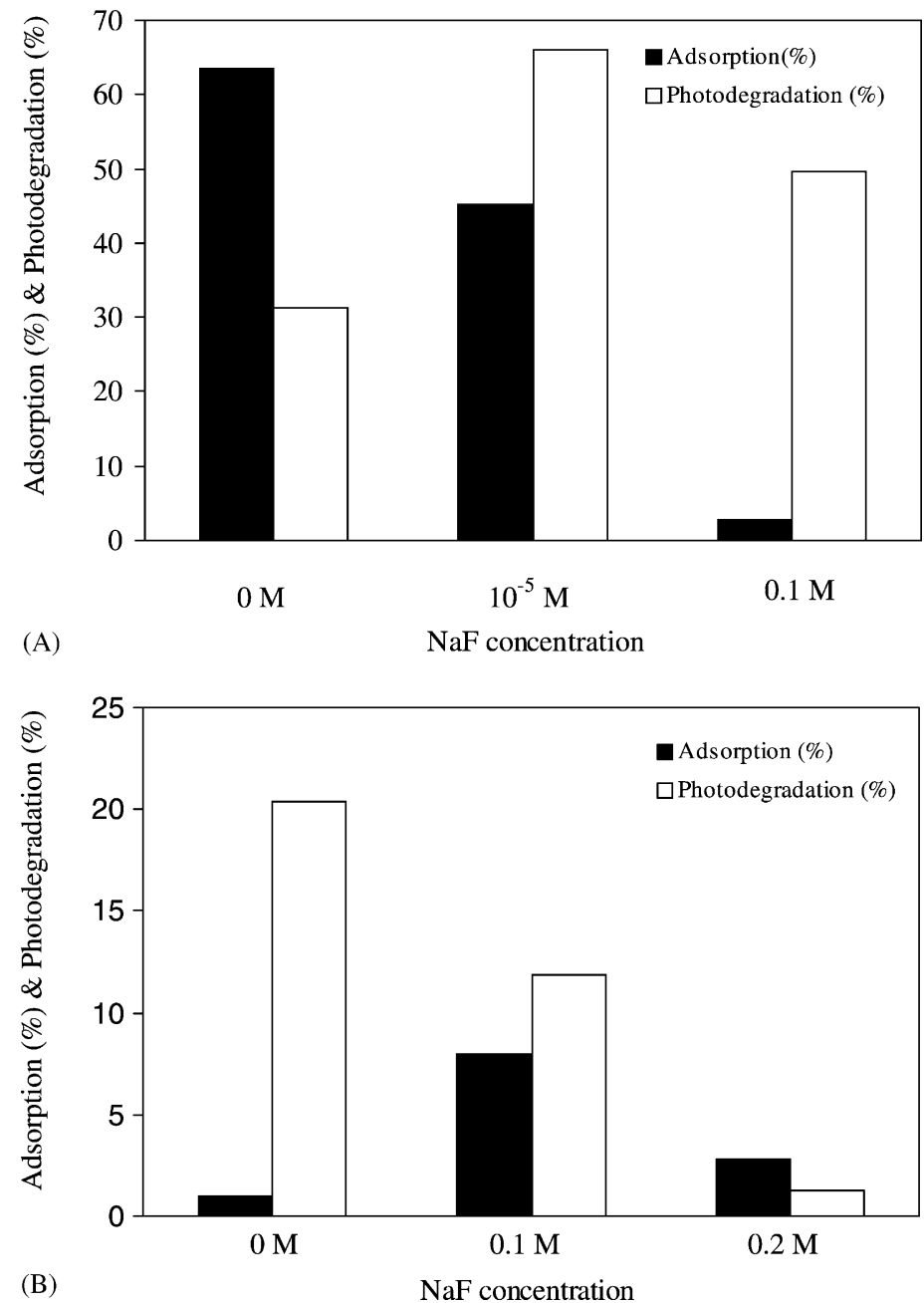

Fig. 8. The effects of different concentrations of $\mathrm{NaF}$ on the adsorption and photodegradation of (A) MX-5B (irradiation time: 20 min) and (B) CBX (irradiation time: $10 \mathrm{~min})$ at $\mathrm{pH} 2.4\left(\left[\mathrm{TiO}_{2}\right]=500 \mathrm{mgl}^{-1}, C_{0}=40 \mathrm{mg} \mathrm{l}^{-1}, \mathrm{UV}=4.2 \mathrm{~mW} \mathrm{~cm}^{-2}\right)$. 
adsorption of MX-5B onto the surface of $\mathrm{TiO}_{2}$. Meanwhile, appropriate amounts of $\mathrm{NaClO}_{4}$ enhanced the photocatalytic decolorization rate of $\mathrm{MX}-5 \mathrm{~B} . \mathrm{ClO}_{4}{ }^{-}$ played the same role as those of $\mathrm{SO}_{4}{ }^{2-}$ and $\mathrm{H}_{2} \mathrm{PO}_{4}{ }^{-}$. At $\mathrm{pH} 10.8, \mathrm{ClO}_{4}{ }^{-}$decreased the photoactivity of $\mathrm{TiO}_{2}$. The $\mathrm{ClO}_{4}{ }^{-}$in solution trapped ${ }^{\bullet} \mathrm{OH}$ to decrease the decolorization rate of MX-5B.

\subsubsection{Effect of $F^{-}$}

$\mathrm{F}^{-}$showed different effects for the photodegradation of MX-5B and CBX. In general, the adsorption of MX-5B decreased with $\mathrm{F}^{-}$concentration at $\mathrm{pH} 2.4$ (Fig. 8A). The maximum photocatalytic decolorization rate of MX-5B was observed at $10 \mu \mathrm{M}$ of $\mathrm{F}^{-}$. The photodegradation rate started to drop in the presence of higher $\mathrm{F}^{-}$concentrations. The behavior of $\mathrm{F}^{-}$was similar to the above-mentioned effect of ions on photocatalytic activity. On the contrary, there was no correlation between the adsorption amount of CBX and $\mathrm{F}^{-}$concentration at $\mathrm{pH} 2.4$ (Fig. 8B). Moreover, the photocatalytic activity was markedly inhibited with the addition of $\mathrm{F}^{-}$to solution. The result indicated that $\mathrm{F}^{-}$ mainly trapped $\mathrm{h}^{+}$and $\bullet{ }^{\bullet} \mathrm{OH}$ affecting the photodegradation of MX-5B, while its adsorption on the surface of $\mathrm{TiO}_{2}$ could not change the charge arrangement of $\mathrm{TiO}_{2}$ surface at $\mathrm{pH}$ 2.4. Fig. 9A and $\mathrm{B}$ shows that the lowering $\mathrm{F}^{-}$concentration decreases the photodegradation of MX-5B and CBX at strong basic conditions.
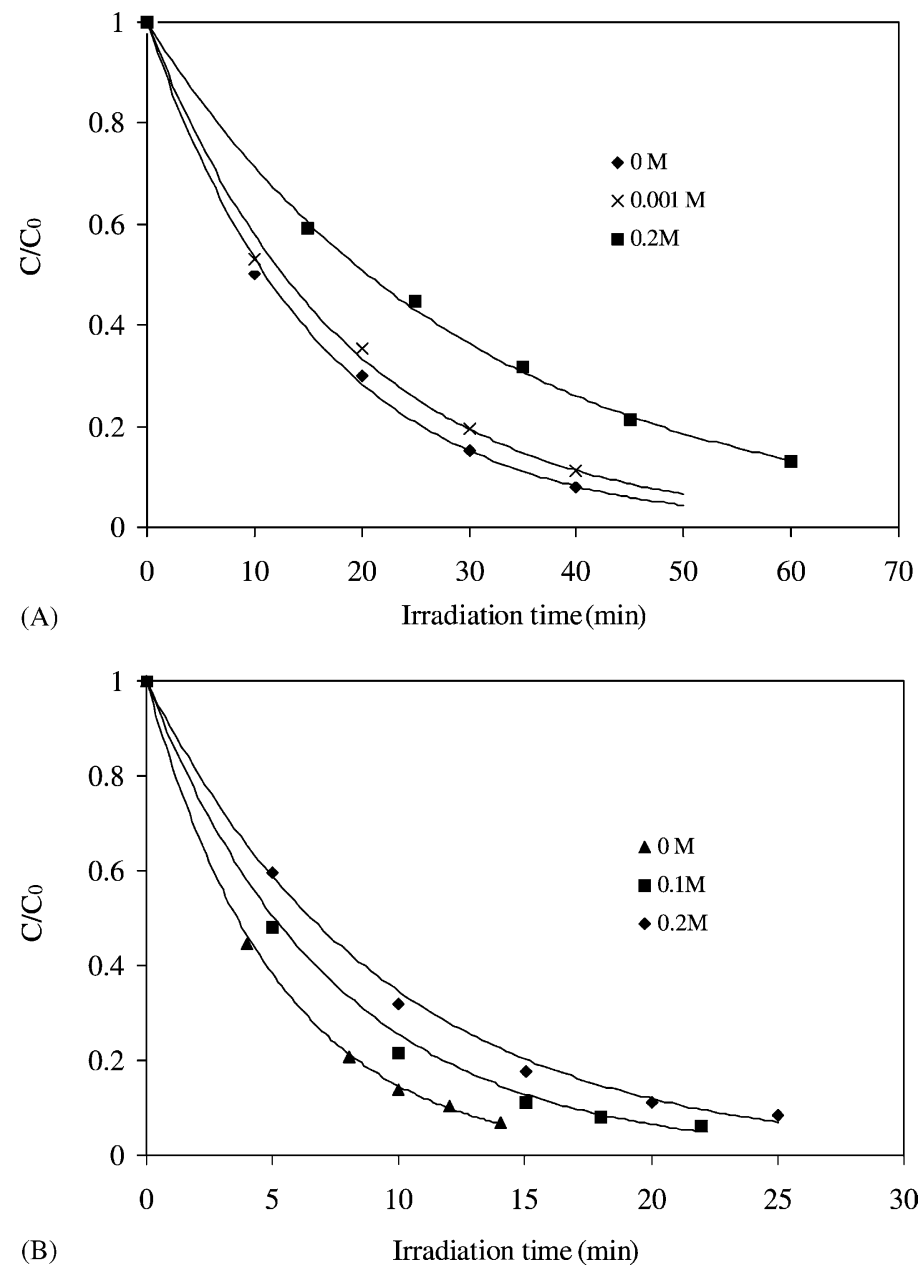

Fig. 9. The effect of NaF on the photodegradation of (A) MX-5B at pH 10.8 and (B) $\mathrm{CBX}$ at $\mathrm{pH} 8.0\left(\left[\mathrm{TiO}_{2}\right]=500 \mathrm{mg}^{-1}, C_{0}=40 \mathrm{mg} \mathrm{l}^{-1}\right.$, $\mathrm{UV}=4.2 \mathrm{~mW} \mathrm{~cm}^{-2}$ ). 


\subsection{Effects of $\mathrm{Cu}^{2+}$ and $\mathrm{Ni}^{2+}$ on the photodegradation rates of dyes}

Fig. 10A and $\mathrm{B}$ shows the changes of the photodegradation rates of $\mathrm{MX}-5 \mathrm{~B}$ with $\mathrm{Cu}\left(\mathrm{NO}_{3}\right)_{2}$ and $\mathrm{Ni}\left(\mathrm{NO}_{3}\right)_{2}$ concentrations at $\mathrm{pH}$ 2.4. The photocatalytic decolorization rate of MX-5B slightly increased in the presence of $1 \mu \mathrm{M}$ of $\mathrm{Cu}^{2+}$ and $\mathrm{Ni}^{2+}$. No significant relationship between the adsorption of MX-5B and the addition of metal ions was observed in all experiments. Over the tested $\mathrm{pH}$ range, the principal cationic ions in the solution were $\mathrm{Cu}^{2+}$ and $\mathrm{Ni}^{2+}$.
They affected the PCO of organics by trapping electrons. Their reduced forms could trap holes and that might explain the decrease of the $\mathrm{e}^{-} / \mathrm{h}^{+}$recombination rate and a higher production of ${ }^{\bullet} \mathrm{OH}$. Excess $\mathrm{Cu}^{2+}$ and $\mathrm{Ni}^{2+}$ led to the short-circuiting reactions, which created a cyclic process without generating active ${ }^{\bullet} \mathrm{OH}$, and retarded the reaction. The reaction schemes are shown in the following equation (Eqs. (3) and (4)):

$$
\mathrm{Cu}^{2+}\left(\mathrm{Ni}^{2+}\right)-\mathrm{e}^{-} \rightarrow \mathrm{Cu}^{+}\left(\mathrm{Ni}^{+}\right)-\mathrm{e}^{-} \rightarrow \mathrm{Cu}(\mathrm{Ni})
$$

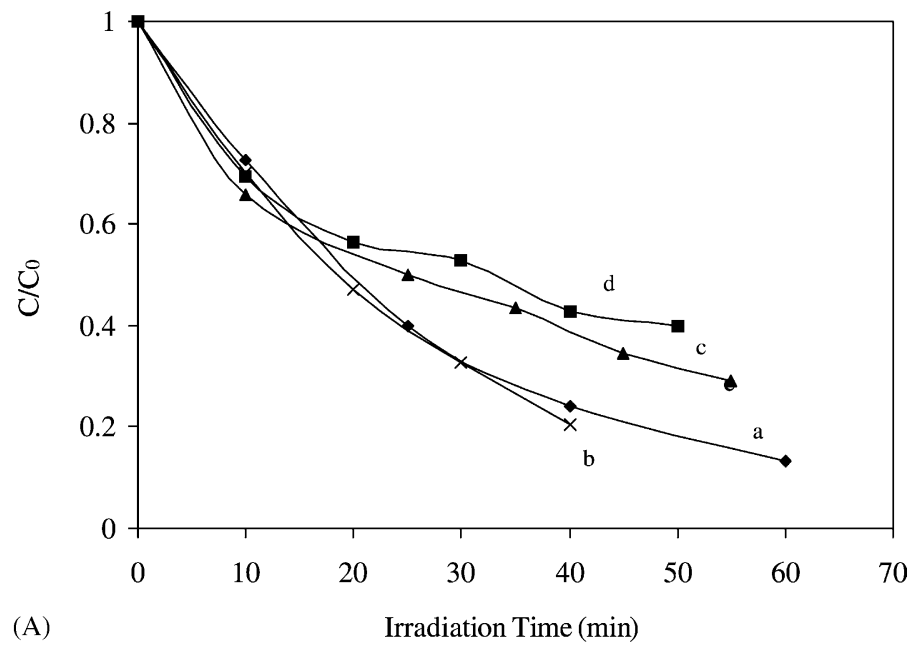

(A)

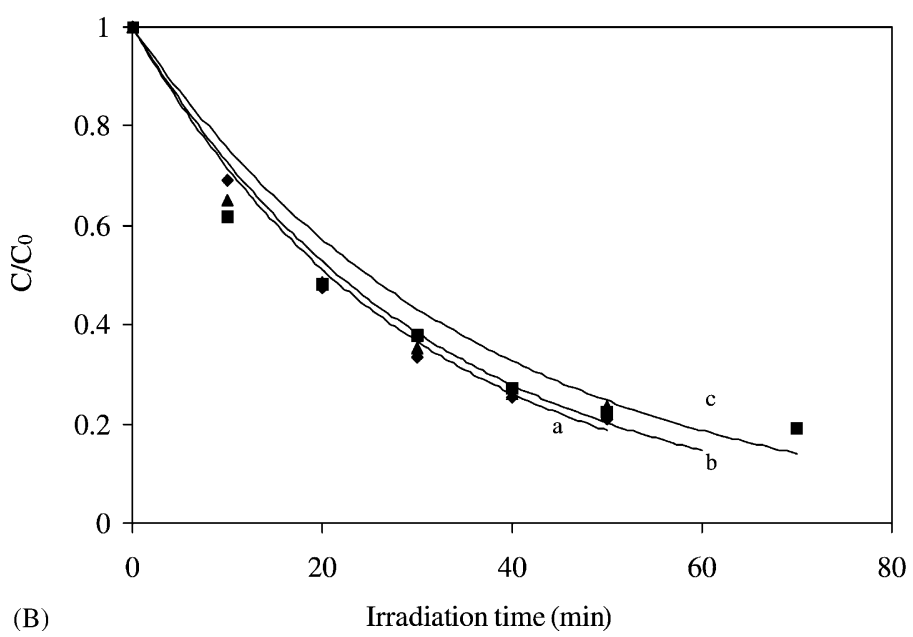

Fig. 10. The effects of (A) $\mathrm{Cu}^{2+}(a=0 \mu \mathrm{M}, b=1 \mu \mathrm{M}, c=10 \mu \mathrm{M}$ and $d=33 \mu \mathrm{M})$, and (B) $\mathrm{Ni}^{2+}(a=0 \mu \mathrm{M}, b=1 \mu \mathrm{M}$ and $c=10 \mu \mathrm{M})$ on the photodegradation of MX-5B at $\mathrm{pH} 2.4\left(\left[\mathrm{TiO}_{2}\right]=500 \mathrm{mgl}^{-1}, C_{0}=40 \mathrm{mgl}^{-1}, \mathrm{UV}=4.2 \mathrm{~mW} \mathrm{~cm}^{-2}\right)$. 
$\mathrm{Cu}(\mathrm{Ni})-\mathrm{h}^{+} \rightarrow \mathrm{Cu}^{+}\left(\mathrm{Ni}^{+}\right)-\mathrm{h}^{+} \rightarrow \mathrm{Cu}^{2+}\left(\mathrm{Ni}^{2+}\right)$

Under acidic conditions, $63 \%$ of added MX-5B was adsorbed onto the surface of $\mathrm{TO}_{2}$ to inhibit trapping of $\mathrm{e}^{-}$and $\mathrm{h}^{+}$by $\mathrm{Cu}^{2+}$ and $\mathrm{Ni}^{2+}$. However, at $\mathrm{pH}$ 10.8 , the photodegradation of MX-5B was completely inhibited by the trace quantities of $\mathrm{Cu}^{2+}$ and $\mathrm{Ni}^{2+}$ (Fig. 11A and B). Under this experimental condition, the principle ions in solution were $\mathrm{Cu}^{2+}$ and $\mathrm{Ni}^{2+}$. No significant adsorption of MX-5B onto the surface of $\mathrm{TiO}_{2}$ was observed under the basic condition. $\mathrm{Cu}^{2+}$ and $\mathrm{Ni}^{2+}$ trapped the electron-hole pair more easily than that in acidic condition. $\mathrm{Ni}^{2+}$ showed a stronger influence than $\mathrm{Cu}^{2+}$. It has been reported [17] that the following oxidation reaction is thermodynamically favored at $\mathrm{pH}>9$. Therefore, some $\mathrm{Ni}^{2+}$ formed $\mathrm{NiO}_{2}$ deposition on the surface of $\mathrm{TiO}_{2}$, and deactivated the photocatalyst (Eq. (5)):

$2 \mathrm{Ni}^{2+}+2 \mathrm{O}_{2}+2 \mathrm{H}_{2} \mathrm{O} \rightarrow 2 \mathrm{NiO}_{2(\mathrm{~s})}+4 \mathrm{H}^{+}$

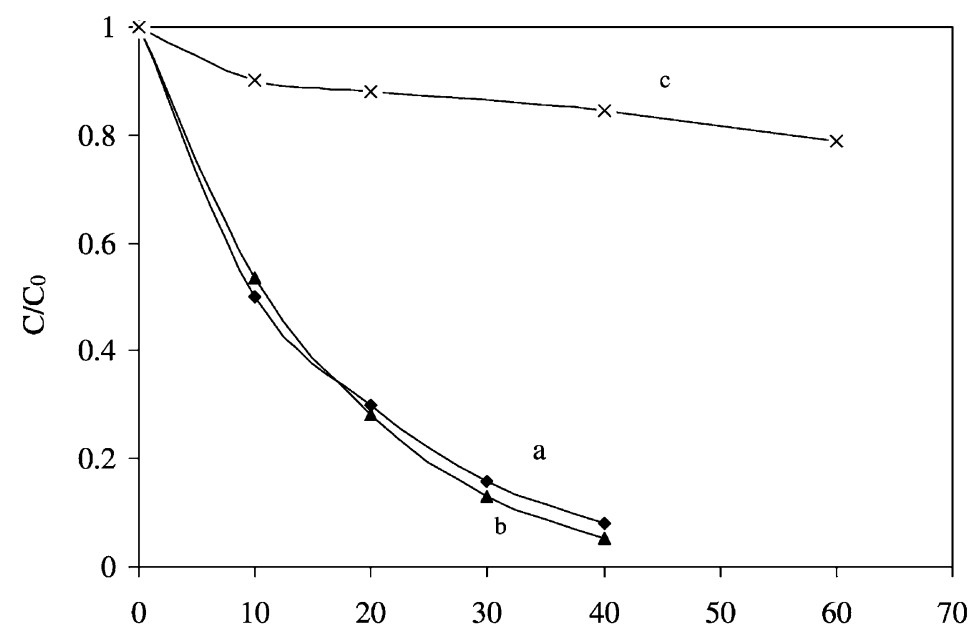

(A)

Irradiation Time (min)

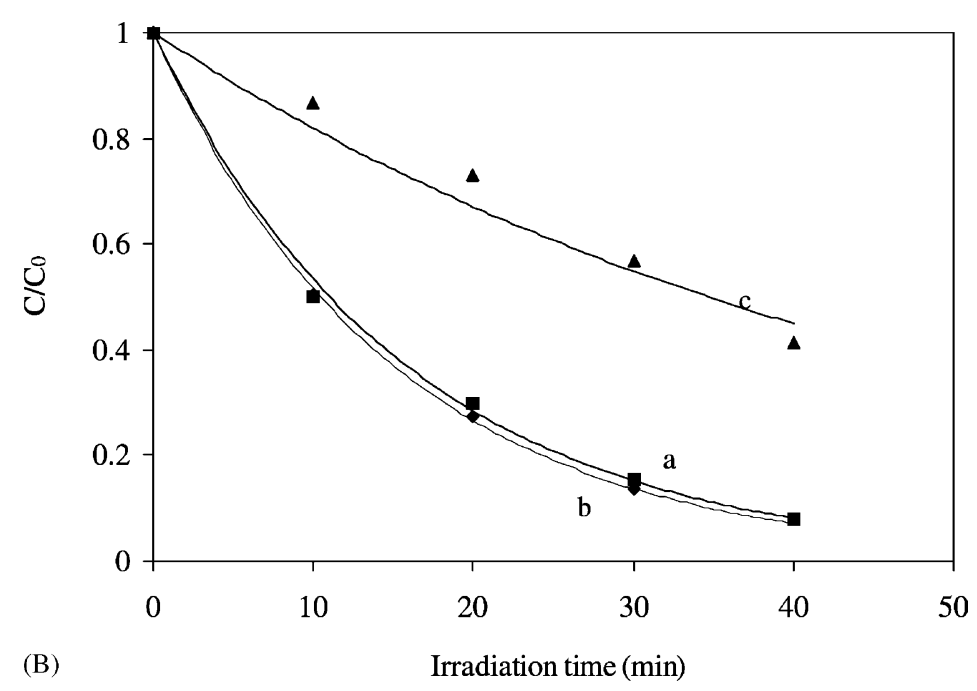

Fig. 11. The effects of (A) $\mathrm{Cu}^{2+}(a=0 \mu \mathrm{M}, b=10 \mu \mathrm{M}$ and $c=33 \mu \mathrm{M})$ and (B) $\mathrm{Ni}^{2+}(a=0 \mu \mathrm{M}, b=10 \mu \mathrm{M}$ and $c=10 \mu \mathrm{M})$ on the photodegradation of MX-5B under $\mathrm{pH} 10.8\left(\left[\mathrm{TiO}_{2}\right]=500 \mathrm{mgl}^{-1}, C_{0}=40 \mathrm{mgl}^{-1}, \mathrm{UV}=4.2 \mathrm{~mW} \mathrm{~cm}^{-2}\right)$. 


\section{Conclusions}

Results in this study indicate that the adsorption and photocatalytic degradation (decolorization) of two azo dyes, namely, MX-5B and CBX, are very different. Aqueous phase reactions favored the decolorization of MX-5B, while photodegradation of CBX took place mainly on the surface of $\mathrm{TiO}_{2}$. The difference was due to the difference in physico-chemical properties of two azo dyes. In order to efficiently treat target azo dyes by $\mathrm{PCO}$, the appropriate $\mathrm{pH}$ should be used for specific azo dye.

In addition, the presence of various inorganic ions such as $\mathrm{SO}_{4}{ }^{2-}, \mathrm{H}_{2} \mathrm{PO}_{4}{ }^{-}, \mathrm{ClO}_{4}{ }^{-}, \mathrm{F}^{-}, \mathrm{Cu}^{2+}$ and $\mathrm{Ni}^{2+}$ that are frequently found to be co-exist with azo dyes in industrial effluent. Anions such as $\mathrm{SO}_{4}{ }^{2-}, \mathrm{H}_{2} \mathrm{PO}_{4}{ }^{-}$, $\mathrm{ClO}_{4}{ }^{-}$and $\mathrm{F}^{-}$generally increased the photodegradation rates of MX-5B and CBX in acidic solutions, while these anions inhibited the activity of the photocatalyst $\left(\mathrm{TiO}_{2}\right)$ by trapping $\mathrm{h}^{+}$and ${ }^{\bullet} \mathrm{OH}$ under both acidic and basic conditions. Also the presence of trace quantities of $\mathrm{Cu}^{2+}$ and $\mathrm{Ni}^{2+}$ were detrimental for the photodegradation MX-5B at $\mathrm{pH} 10.8$. In the presence of these inorganic ions, the optimum $\mathrm{pH}$ for specific azo dye degradation by PCO should be considered in order to achieve the maximal treatment efficiency.

\section{Acknowledgements}

The study was supported by a research grant of Research Grant Council, Hong Kong SAR Government to P.K. Wong and J.C. Yu, and a research grant of National Science Foundation of China (Contract
No. 20007004) and the National 863 Project of China (2002AA6409040) to C. Hu.

\section{References}

[1] D.F. Ollis, E. Pelizzetti, N. Serpone, Environ. Sci. Technol. 25 (1991) 1523.

[2] J.G. Yu, J.C. Yu, W.R. Ho, Z.T. Jiang, N. J. Chem. 26 (2002) 607.

[3] J.C. Crittenden, Y. Zhang, D.W. Hand, D.L. Perram, E.G. Marchand, Water Environ. Res. 68 (1996) 270.

[4] M.R. Hoffmann, S.T. Martin, W. Choi, Chem. Rev. 95 (1995) 69.

[5] M. Abdullah, G.K.C. Low, R.W. Matthews, J. Phys. Chem. 94 (1990) 6820.

[6] R.M. Matthews, J. Chem. Soc., Faraday Trans. 1 (1984) 457.

[7] J.E. Pacheco, M.R. Prairie, L. Yellowhorse, J. Solar Energy Eng. 115 (1993) 123.

[8] H. Zhu, M. Zhang, Z. Xia, G.K.C. Low, Water Res. 29 (1995) 2681.

[9] R.A. Burns, J.C. Crittenden, D.W. Hand, J. Environ. Eng. 1 (1999) 77

[10] G. Liu, T. Wu, J. Zhao, H. Hidaka, N. Serpone, Environ. Sci. Technol. 33 (1999) 2081.

[11] C. Hu, Y.Z. Wang, Chemosphere 39 (1999) 2107.

[12] J. Kiwi, C. Pulgarin, P. Peringer, M. Gratzel, Appl. Catal. B: Environ. 3 (1993) 85.

[13] C. Hu, J.C. Yu, Z. Hao, P.K. Wong, Appl. Catal. B: Environ. 42 (2003) 47.

[14] C. Hu, Y.C. Tang, J.C. Yu, P.K. Wong, Appl. Catal. B: Environ. 40 (2003) 131.

[15] C. Hu, Y.Z. Wang, H.X. Tang, Appl. Catal. B: Environ. 35 (2001) 95.

[16] A.B. Ross, P. Neta, Rate constants for reactions of inorganic radicals in aqueous solution, US Department of Commerce, National Bureau of Standards, Washington, DC, 1979.

[17] D.R. Lide, CRC Handbook of Chemistry and Physics, 74th ed., CRC Press, Boca Raton, 1993. 